\title{
Notes on the vocalizations of Brownish-flanked Bush-warbler (Cettia fortipes)
}

\section{Peter Boesman}

In the following we briefly analyze and compare voice of the different races of Brownishflanked Bush-warbler (Cettia fortipes). We also try to quantify the extent of any vocal differences using the criteria proposed by Tobias et al. (2010), as a support for taxonomic review. We have made use of sound recordings available on-line from Xeno Canto (XC).

Song is structurally similar to e.g. Cettia diphone but higher-pitched: a long pure whistle (sometimes preceded by a single or several short notes) followed by a short loud phrase of several different notes. Our main interest is to compare the Taiwanese race with the mainland races. An overview:

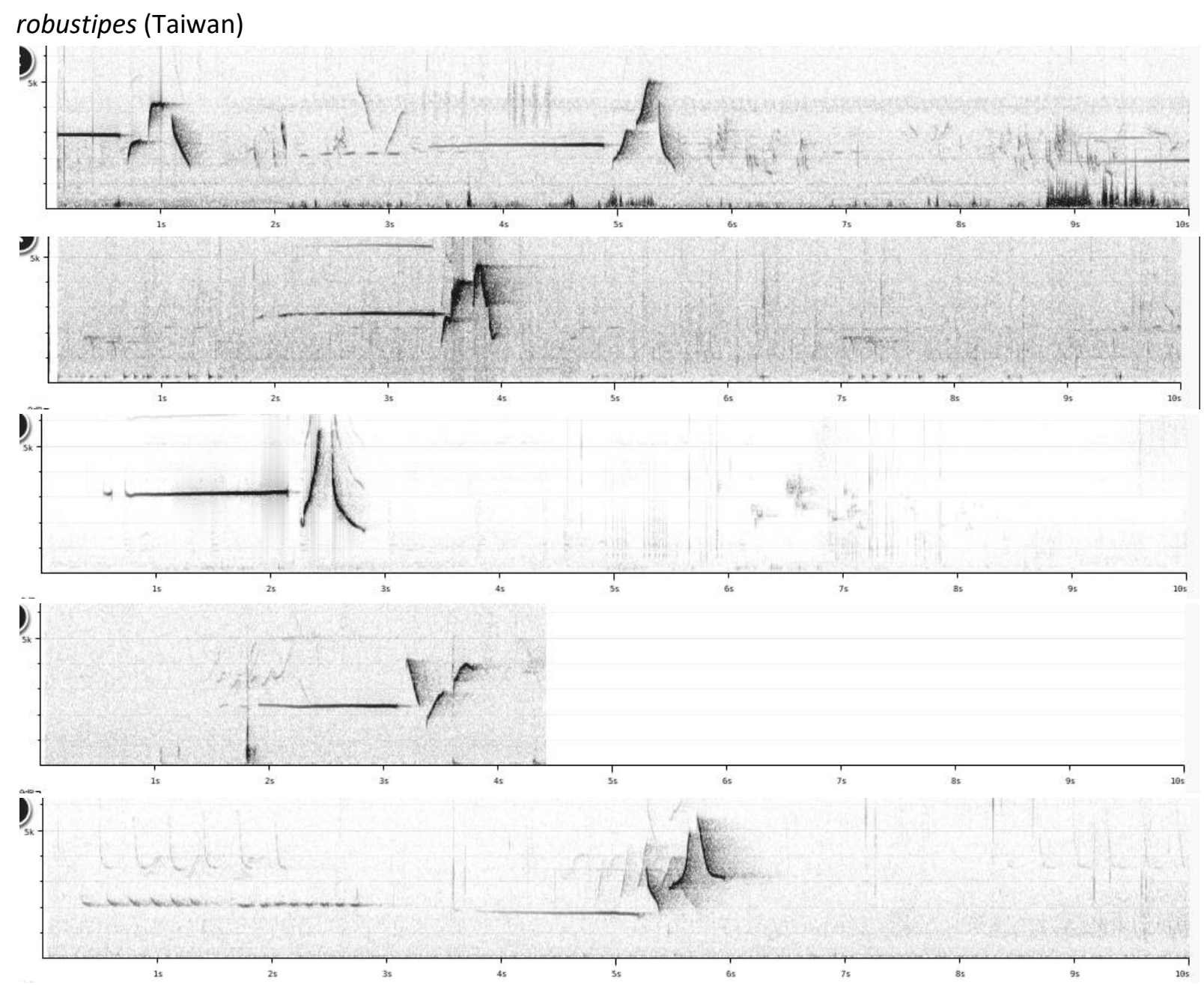




\section{HANDBOOK OF THE \\ BIRDS PF,THE WORLD Alve}

\section{ORNITHOLOGICAL NOTES}

Other races (from west to east):

\section{Pakistan}

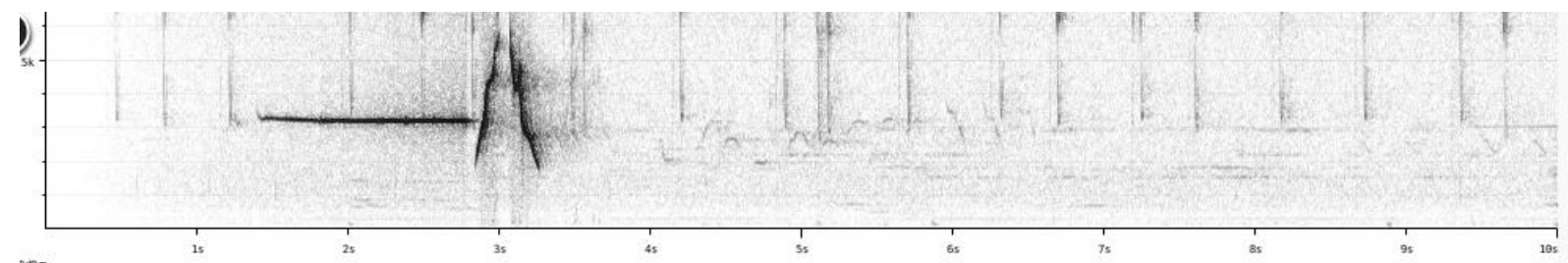

India

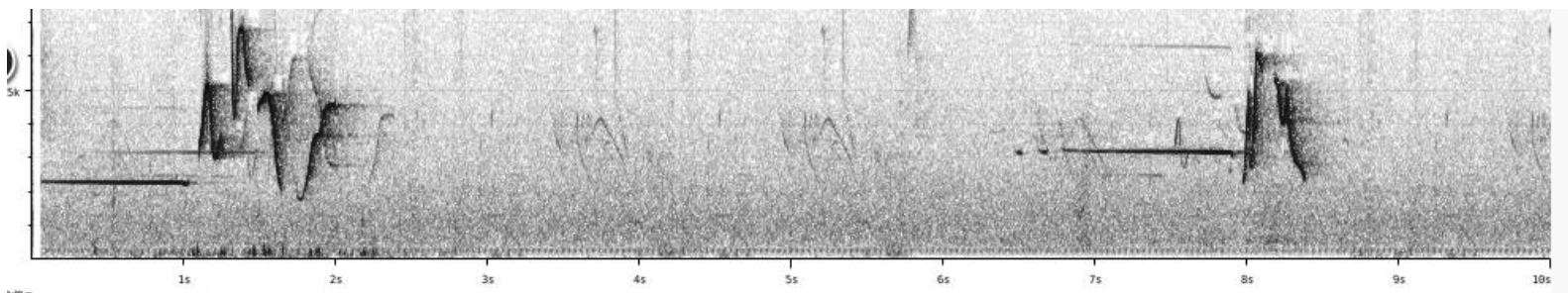

Vietnam

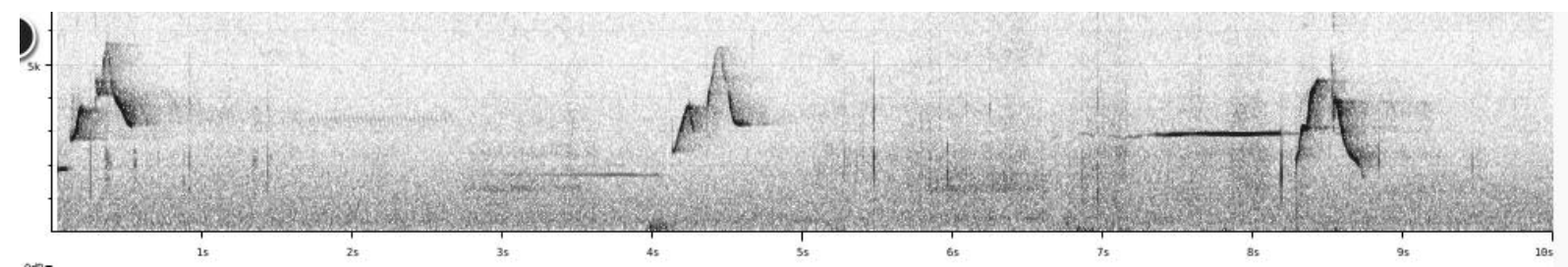

China
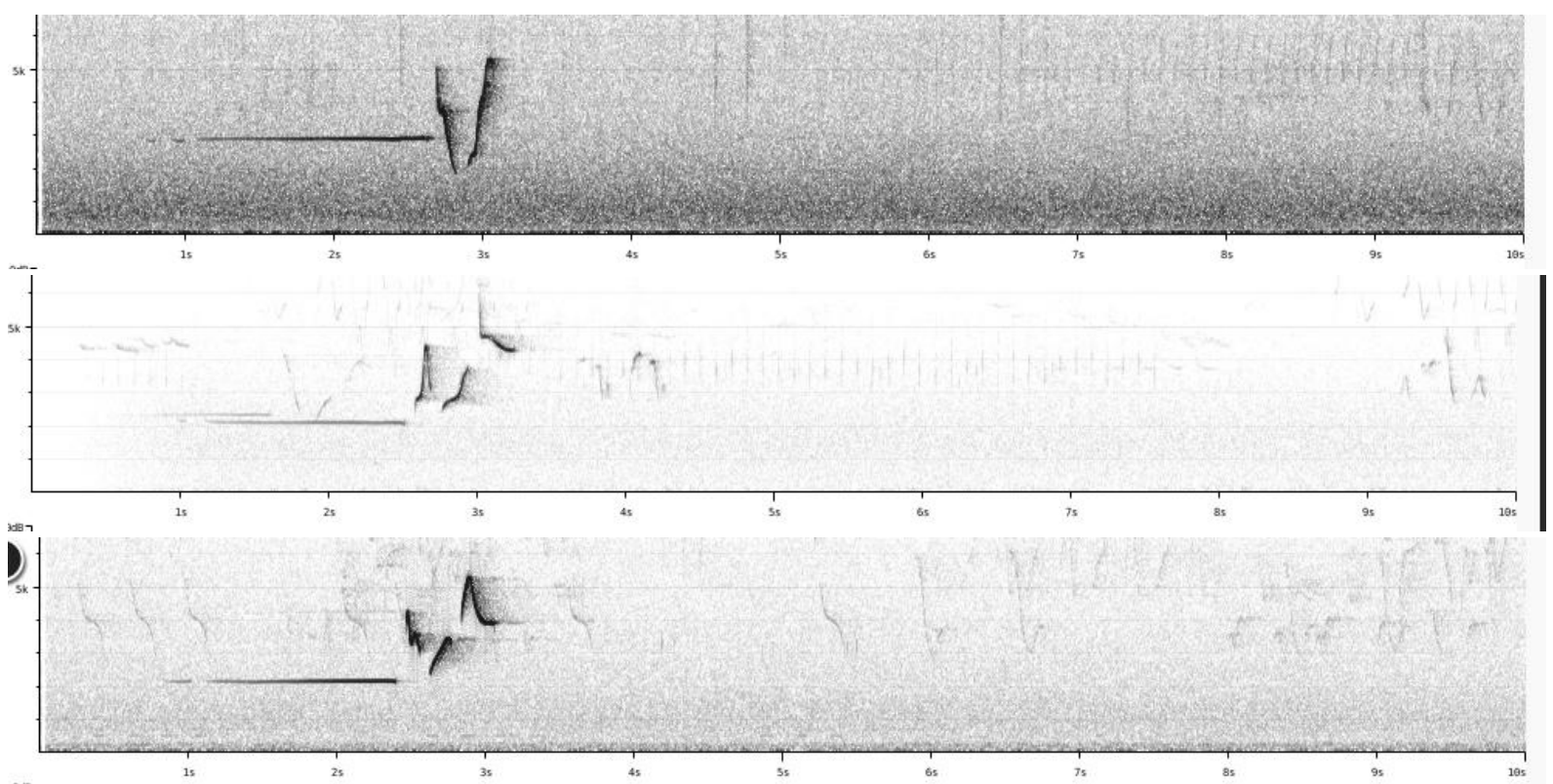

It is clear from the above examples that vocal variation of robustipes falls well within the range of other races. All basic sound parameters (note length, frequency, \# of notes..) are about the same. One minor difference seems to be that robustipes reaches on average lower frequencies in the song phrase (with considerable overlap): $1600-1900 \mathrm{~Hz}(n=7)$ vs $1600-2500 \mathrm{~Hz}$ in other races $(n=15)$ (score 1).

Vocal differences are thus very small. 
This note was finalized on 2nd November 2015, using sound recordings available on-line at that moment. We would like to thank in particular the many sound recordists who placed their recordings for this species on XC:

\section{References}

Tobias, J.A., Seddon, N., Spottiswoode, C.N., Pilgrim, J.D., Fishpool, L.D.C. \& Collar, N.J. (2010). Quantitative criteria for species delimitation. Ibis 152(4): 724-746.

\section{Recommended citation}

Boesman, P. (2016). Notes on the vocalizations of Brownish-flanked Bush-warbler (Cettia fortipes). HBW Alive Ornithological Note 255. In: Handbook of the Birds of the World Alive. Lynx Edicions, Barcelona. (retrieved from http://www.hbw.com/node/932259 on 4 October 2016). 